\title{
Dreissenids' breaking loose: differential attachment as a possible driver of the dominance shift between two invasive mussel species
}

\author{
Anouk D’Hont $(\mathbb{D} \cdot$ Adriaan Gittenberger - A. Jan Hendriks $\mathbb{D} \cdot$ Rob S. E. W. Leuven
}

Received: 28 April 2020/ Accepted: 19 February 2021 / Published online: 19 March 2021

(C) The Author(s) 2021

\begin{abstract}
Ponto-Caspian dreissenids are notorious freshwater invaders. Recently, widespread observations show a dominance shift from the early invader, Dreissena polymorpha, to its successor, Dreissena bugensis. These observations likely reflect congeneric species differences in physiological and behavioural traits. Here, we assessed the mussel attachment strength, attachment rate, and the mode of byssal failure as trait differences that could potentially contribute to dominance shifts. The attachment traits were measured in field and laboratory experiments. Fouling plates were deployed in the Rhine-Meuse
\end{abstract}

Supplementary Information The online version contains supplementary material available at https://doi.org/10.1007/ s10530-021-02492-w.

A. D'Hont $(\varangle) \cdot$ A. Gittenberger

GiMaRIS, Marine Research Inventory and Strategy

Solutions, Rijksstraatweg 75, 2171 AK Sassenheim, The

Netherlands

e-mail: anouk.dhont91@gmail.com

A. D'Hont · R. S. E. W. Leuven

Department of Animal Ecology and Physiology, Institute for Water and Wetland Research, Radboud University, Heyendaalseweg 135, 6525 AJ Nijmegen, The

Netherlands

A. Gittenberger

Department of Marine Zoology, Naturalis Biodiversity

Center, Pesthuislaan 7, 2333 BA Leiden, The Netherlands river delta and dreissenids were collected and acclimatised in $60 \mathrm{~L}$ non-aerated freshwater tanks. Attachment strength was positively correlated with shell size. The attachment strength of $D$. bugensis was significantly greater compared to slower growing $D$. polymorpha individuals of a dreissenid field assemblage. This corresponded to the superior byssal thread morphology of $D$. bugensis (i.e. higher number and two times wider byssal threads). Moreover, our results indicated that byssal threads of $D$. bugensis are stronger than those of D. polymorpha, as the latter ruptured more often. Additionally, D. bugensis had a significantly lower attachment rate than $D$. polymorpha. Having a greater attachment strength gives $D$. bugensis an advantage when it comes to withstanding
A. J. Hendriks
Department of Environmental Science, Institute for Water and Wetland Research, Radboud University, Heijendaalseweg 135, 6525 AJ Nijmegen, The Netherlands
R. S. E. W. Leuven
Netherlands Centre of Expertise on Exotic Species
(NECE), Nature Plaza, P.O. Box 9010,
6500 GL Nijmegen, The Netherlands 
currents and predators. On the other hand, not being attached allows an individual to actively move around. This would allow them to move away from fast changing unfavourable environmental conditions. These attachment traits indicate competitive benefits for D. bugensis over D. polymorpha, therefore possibly contributing to the dominance shifts.

Keywords Attachment strength - Byssus threads . Detachment location · Quagga mussel · Shell size . Zebra mussel

\section{Introduction}

Both the zebra mussel Dreissena polymorpha (Pallas 1771) and the quagga mussel Dreissena bugensis (also described as Dreissena rostriformis bugensis auct., Andrusov 1897; Wesselingh et al. 2019) have successfully invaded hard, freshwater substrates in large parts of Europe and North America (Karatayev et al. 2011; Matthews et al. 2014; Collas et al. 2018). Dreissena polymorpha was introduced in Western Europe at the beginning of the nineteenth century (Van der Velde et al. 2010; Sousa et al. 2011). Dreissena bugensis spread in the same area during the midtwentieth century (Therriault et al. 2005). This led to the co-occurrence of both species in their native (Zhulidov et al. 2004) and introduced areas (Grutters et al. 2012). During the last decades, there have been widespread observations of a shift going from the first introduced $D$. polymorpha to the recent invader $D$. bugensis as the dominant species (Matthews et al. 2014; Marescaux et al. 2015; Ginn et al. 2018). These shifts were for example observed in the 1970s in their native area in Ukraine (Wesselingh et al. 2019) and in the 1990s in introduced regions in the Great Lakes in North America (Ricciardi and Whoriskey 2004). Only a few studies have assessed mechanisms driving this dominance shift (D'Hont et al. 2018). These studies so far found that although $D$. polymorpha is able to settle earlier in the season, is more salinity tolerant, and predators seem to target this species less than $D$. bugensis, D. bugensis usually remains dominant where both species co-occur (Karatayev et al. 2014; Naddafi and Rudstam 2014; D'Hont et al. 2018). Dreissena bugensis is able to settle in a wider range of habitats, is found at a greater depth range, grows faster and larger and adjusts its growth and settlement better to seasonally and annually varying salinities and temperatures than D. polymorpha (Claxton and Mackie 1998; Orlova et al. 2005; Gerstenberger et al. 2011; Metz et al. 2018). Dreissena bugensis is known to have a higher assimilation efficiency, a higher activity of certain enzymes, higher filtration rates and lower respiration rates (Stoeckmann 2003; Ram et al. 2012; Karatayev et al. 2014). Moreover, this species has lower winter mortality, has a higher resistance to cold temperature and settles in higher numbers when $D$. polymorpha individuals are already present on the substrate (Orlova et al. 2005; D'Hont et al. 2018). These characteristics proved a competitive benefit for $D$. bugensis over D. polymorpha. However, several other plausible mechanisms have not been studied extensively, such as differences between both species in mobility, attachment strength and detachment ability (Peyer et al. 2009; Balogh et al. 2019).

Both dreissenid species attach to hard substratum using byssal threads secreted by the byssus gland at the base of the foot of the mussel (Kobak et al. 2009). Biofouling of hard substrates such as rock, wood, ship hulls, hydraulic engineering structures and water intake facilities causes severe environmental problems and high economic costs (Pimentel et al. 2005; Grutters et al. 2012). Moreover, other species e.g. crayfish or native freshwater mussels can be smothered to death by heavy fouling of dreissenids, blocking their siphons and competing for resources (Ricciardi et al. 1996; Sousa et al. 2011; Gonçalves et al. 2013; Bódis et al. 2014).

Comparative studies on the attachment traits of both dreissenids are relatively scarce as most studies have so far focused on D. polymorpha (Ackerman et al. 1996; Dormon et al. 1997; Kobak et al. 2009; Czarnołęski et al. 2010). Moreover, in situ field data is lacking making it difficult to interpret attachment traits in natural communities (Kobak 2001). Studies assessing the attachment strength and byssal thread synthesis rate in laboratory setups found higher values for $D$. polymorpha compared to D. bugensis (Peyer et al. 2009; Grutters et al. 2012; Collas et al. 2018). Balogh et al. (2019) unravelled a more complex pattern as the attachment strength increased with shell size. For larger individuals the previously observed pattern reversed as larger $(>1.2 \mathrm{~cm})$ D. bugensis individuals had a higher attachment strength than $D$. polymorpha 
individuals of the same size (Balogh et al. 2019). Next to the shell size, the number and thickness of byssal threads have a positive impact on the attachment strength of dreissenids as well (Bell and Gosline 1997; Kobak 2006). Additionally, the comparison between the natural detachment mechanisms of both dreissenids is lacking. The common blue mussel (Mytilus edulis) is known to voluntary detach its entire byssal mass (Eckroat et al. 1993). Voluntary detachment is also known for D. polymorpha individuals (Kobak et al. 2009; Dzierżyńska-Białończyk et al. 2018). However, the mechanism behind this voluntary detachment is not well understood (Eckroat et al. 1993; Kobak et al. 2009). Most dreissenid attachment studies focus on the forced detachment of the PontoCaspian mussels. The mode of byssal failure or detachment location of dreissenids indicates the part of the attachment structure (adhesive plaques, byssal threads or stem detachment) that ruptures during forced detachment of an individual (Dormon et al. 1997). Adhesive plaque detachment is mostly due to the detachment of the glue from the substrate. The byssal threads themselves can rupture as well. The rupture of the stem (where all byssal threads are joined together) from the byssal gland causes the entire byssal mass to be separated from the mussel. To our knowledge, our study was the first comparative assessment of the detachment location of both species. Dormon et al. (1997) studied the detachment location of D. polymorpha individuals. They found that the force required to detach the mussels was directly proportional to the percentage of broken byssal threads and to the detachment location.

It has been proven that the presence of other species, might affect dreissenid behaviour. This effect of species assemblage has been assessed by comparing syntopic populations (both D. polymorpha and D. bugensis together) and allotopic populations (either D. polymorpha or D. bugensis) to each other. D'Hont et al. (2018) found that a higher number of $D$. bugensis settled when $D$. polymorpha individuals were already present on the substrate. However, the effect of the presence of $D$. bugensis on the $D$. polymorpha attachment rate (whether an individual attached to the substrate or not) and vice versa is not yet known. The effect of the light regime on the attachment rate of both species has not been thoroughly studied either. Generally, D. polymorpha individuals prefer dark environments as they have higher attachment rates in dark environments (Kobak
2013; Kobak et al. 2009; D’Hont et al. 2018). However, no such preference for dark environments was found for D. bugensis individuals on field deployed fouling plates (D’Hont et al. 2018).

This study aimed at unravelling whether differences in attachment traits of both dreissenid species might affect the outcome of interspecific competition. A stronger attachment or higher attachment rate might cause a competitive benefit when it comes to withstanding predation and environmental disturbances such as rapid changes in water level and flow velocity of rivers and canals, caused for example by upstream rainfall or by ship-induced currents (Koopman et al. 2018). On the other hand, being able to detach faster and easier might help mussels to relocate to a more suitable habitat in case of sudden unfavourable environmental changes (e.g. light, temperature, salinity). This way, an individual has a higher chance of reaching its ideal environment where it can thrive. Consequently, the attachment traits of dreissenids can to some degree be one of the drivers of the observed dominance shift between both species, especially in rapidly changing environments. Therefore, we conducted a comparative study focused on these attachment traits. Balogh et al. (2019) unravelled a more complex pattern in the attachment strength of both dreissenid species when comparing different sized individuals to each other. During our study, we wondered whether a comparison between the frequently selected shell size range $(1-2 \mathrm{~cm})$ in laboratory experiments and the shell size range found in the field would result in a similar pattern. For individuals of the same size, we expected a higher attachment strength for $D$. polymorpha, while for individuals of the same age, we would expect D. bugensis to have a higher attachment strength. This hypothesis is based on the fact that the attachment strength increases with shell size and that $D$. bugensis individuals grow faster and larger than $D$. polymorpha individuals do (D'Hont et al. 2018; Balogh et al. 2019). Additionally, the link between the morphology of the byssal threads (number and thickness) and the attachment strength was assessed. Based on previous studies, we expect a positive relationship between these two attachment traits. The differential attachment rate and whether or not the attachment rate is affected by the species assemblage and light regime was studied as well. Finally, the detachment location for both species and a possible link between the detachment location and the individual's attachment strength was assessed. We would expect that the detachment location 
is related to the attachment strength of an individual and to the strength of its byssal threads. For example, having a lower number of byssal thread failures, combined with a greater attachment strength, could indicate stronger byssal threads for this species. By testing these hypotheses, we aimed at elucidating whether differential attachment and detachment of mussel species can be one of the driving forces behind the observed dominance shift between D. polymorpha and D. bugensis.

\section{Material and methods}

\section{Sampling sites}

The sampling sites of dreissenids for this study were located in the Haringvliet and Hollands Diep, which are a part of the Rhine-Meuse delta in the Netherlands. Individuals of both dreissenid species were collected in front of the sluice in the ferry harbour

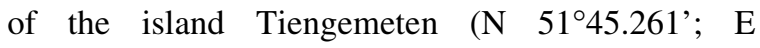
$\left.4^{\circ} 19.046^{\prime}\right)$ and about $8 \mathrm{~km}$ upstream in the same river system at the harbour entrance of Numansdorp (N 5143.037'; E 4²6.211'). Dreissena polymorpha was already present in this area when D. bugensis was observed here for the first time in Western Europe in 2006, after which these species co-existed (Molloy et al. 2007; Schonenberg and Gittenberger 2008). These mussels were monitored ever since using fouling plates of the SETtLement (SETL) project (Gittenberger et al. 2017). Dreissenids were collected at Numansdorp and Tiengemeten in four separate batches on the 19th of December 2017 (batch 1), 6th of March 2018 (batch 2), 12th of June 2018 (batch 3), 5th of December 2018 (batch 4; Fig. 1). These batches consisted of 80 (40 D. bugensis and $40 \mathrm{D}$. polymorpha; batch 1-3) and 200 (100 D. bugensis and 100 D. polymorpha; batch 4) individuals, respectively. In addition to the collection of dreissenids, 21 extra fouling plates were deployed from the floating dock in the ferry harbour of Tiengemeten in June of 2016. Structures in the SETL project consisted of $14 \times 14 \mathrm{~cm}$ sanded PVC plates weighed down by a brick stone and deployed one meter below the water surface (Hines and Ruiz 2001; Schonenberg and Gittenberger 2008; D'Hont et al. 2018). The dreissenids on these SETL plates were considered to be batch 5 measured on the 6th of March 2018 (Fig. 1). Batch
5 consisted of 169 individuals (79 D. polymorpha and 90 D. bugensis).

Field experiment

SETL plates were deployed in front of the sluice in the ferry harbour of the island Tiengemeten for 21 months before retrieval for attachment measurements on the 6th of March 2018 (batch 5; Fig. 1). The attachment strength of 169 dreissenids on field-deployed fouling plates was measured. This number of dreissenids represented all individuals of each species present on the fouling plates, which we will further address as the whole dreissenid field assemblage. For D. polymorpha and $D$. bugensis, this corresponded to a shell size of $0.4-2.0 \mathrm{~cm}$ and $0.4-3.2 \mathrm{~cm}$, respectively.

\section{Laboratory experiment}

The laboratory experiments were conducted with dreissenids from batch 1-4 who all had a shell size between 1 and $2 \mathrm{~cm}$ and were all collected from both Numansdorp and Tiengemeten. After collection in the field, the mussels were acclimatised to room temperature $\left( \pm 20{ }^{\circ} \mathrm{C}\right)$ for 24 to $48 \mathrm{~h}$ after which all byssal threads were cut off using small scissors. Each dreissenid batch was kept in four polyethene tanks each containing $60 \mathrm{~L}$ of non-aerated standing fresh tap water. The tap water had an initial oxygen level of $6.0-8.0 \mathrm{mg} / \mathrm{l}$ and a $\mathrm{pH}$ of 7.84 , temperature of $16.9^{\circ} \mathrm{C}$ and salinity of 0.28 PSU as measured on the second day of the experiment. Within the Haringvliet the $\mathrm{pH}$ normally ranges between 7.7 and 8.6 , the salinity between 0.2 and $0.8 \mathrm{PSU}$ and the temperature between 0 and $28{ }^{\circ} \mathrm{C}$ (Rijkswaterstaat 2020). All tanks were uniformly illuminated with daylight coming through a window at the north side of the laboratory, with a natural photoperiod (batch 1 and 4: 8L:16D, batch 2: 11L:13D, batch 3: 16L:8D).

Attachment traits

\section{Attachment rate}

The attachment rate of 435 dreissenids from batches 1 , 2, 3 and 4 to the hard substrate was assessed. Mussels from each batch were placed in four polyethene tanks (20 individuals per tank for batches 1-3, 50 individuals per tank for batch 4) (Fig. 1). During the 


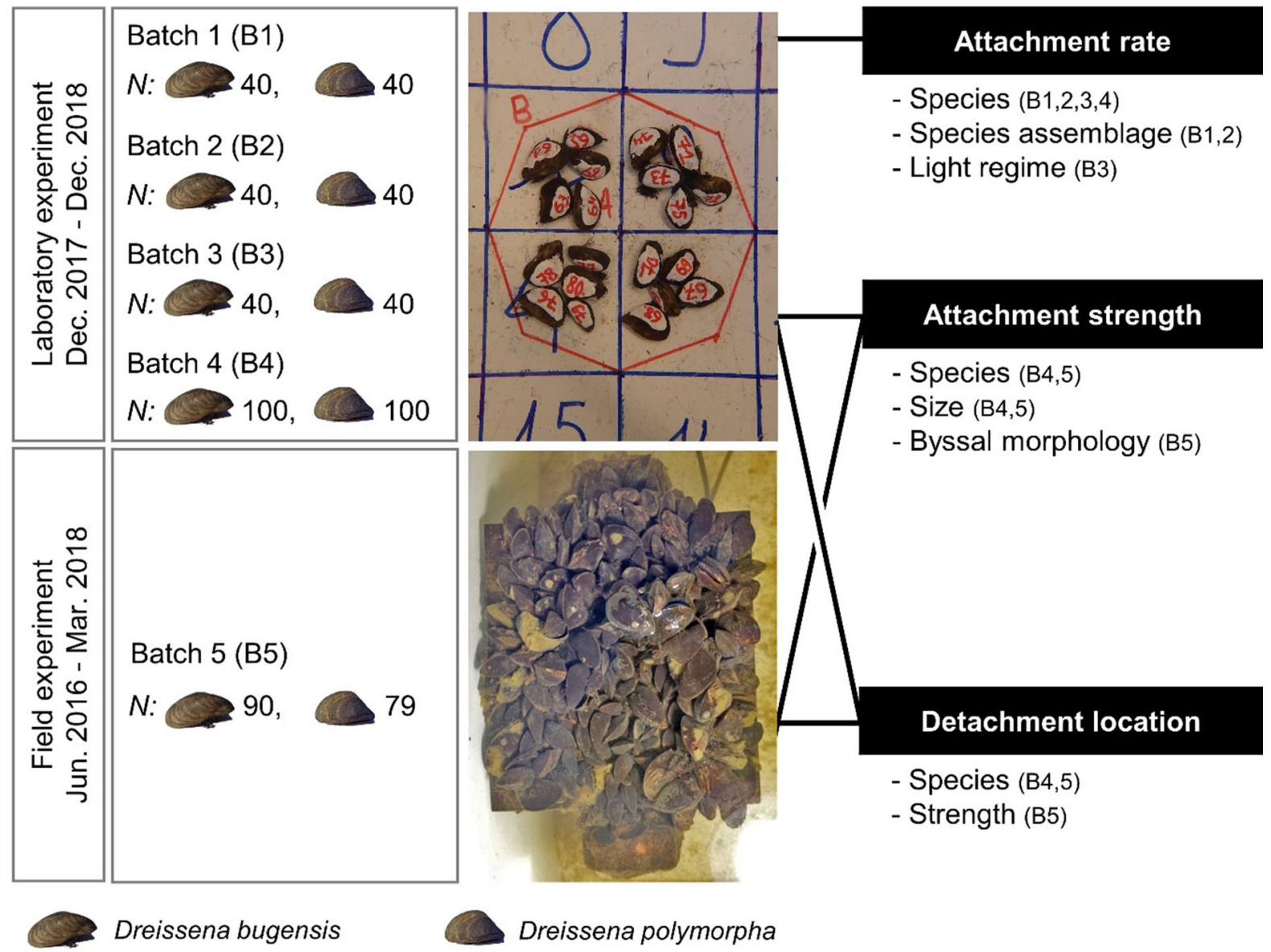

Fig. 1 The setup of the field and laboratory experiments. The number of individuals is indicated by $\mathrm{N}$. The right part of the figure shows the research topics (between brackets: batch(es) of dreissenids used for analyses). For assessing the attachment

experiment with batch 4 five individuals died, explaining the odd number of individuals tested. The experiments to assess the attachment rate of batches 1-4 ran for eleven, four, seven and seven days, respectively. These experiments differed in duration because they were originally designed as a movement experiment by D'Hont et al. (2021). However, as can be seen in our results, the difference in experiment duration had no effect on the number of individuals attached.

Next to the species-specific attachment rate, the effect of the presence of the other species on the attachment rate was assessed. The laboratory setup consisted of two tanks containing a syntopic population (two tanks: 10 D. polymorpha and 10 D. bugensis; 40 individuals in total) and two tanks containing an strength and detachment location, mussels from field and laboratory experiments were used. The attachment rate was derived from laboratory experiments

allotopic population (one tank: 20 D. polymorpha; and one tank: $20 \mathrm{D}$. bugensis; 40 individuals in total). This setup was replicated for batches 1 and 2 for in total 80 individuals for both species.

Batch 3 was used for assessing the effect of light regime on the attachment rate of dreissenids. In total 40 individuals of each species were divided amongst the four tanks, two tanks for each species. One of these two tanks was exposed to a light regime while the other one was kept in the dark at all times $(20 \mathrm{D}$. polymorpha exposed to light and 20 to darkness, $20 \mathrm{D}$. bugensis exposed to light and 20 to darkness). The tanks with light treatment were illuminated by daylight with a natural photoperiod (16L:8D). The dark treatments were achieved by covering the tanks 
with a lid. This exposed the dreissenids to complete darkness, as the tanks were not translucent.

\section{Attachment strength}

The attachment strength was measured for individuals that attached themselves under laboratory circumstances (batch 4), as well as for individuals that attached themselves in the field (batch 5, Fig. 1). This way the attachment strength of mussels in an artificial environment was compared with that of mussels on plates in natural conditions. This comparison allowed for an assessment of the effect of the environment, substrate and attachment duration on the attachment strength of individuals. For the laboratory experiment the attachment strength of 200 mussels (100 D. polymorpha and $100 \mathrm{D}$. bugensis) was measured. The individuals were left to attach for seven days in the four tanks (four times 50 individuals). A duration of seven days was chosen as the attachment strength pattern of D. polymorpha and D. bugensis is supposed to remain equal after seven days, as was found by Balogh et al. (2019) for same sized (1-2 cm) individuals in the laboratory.

The attachment strength of both dreissenid species was measured using a Sauter FK10 digital force gauge (capacity: $10 \mathrm{~N}$, resolution: $0.005 \mathrm{~N}$ ) (Collas et al. 2018). Individuals exceeding the $10 \mathrm{~N}$ limit of the Sauter FK10 digital force gauge were detached using an analogue G\&G $20 \mathrm{~N}$ spring balance. A harness of fishing wire was used to get hold of the mussel on each of both sides of the byssal threads (Fig. 2). Mussels were attached to the force gauge and detached from the substrate by gently pulling up the force gauge vertically and perpendicular to the substrate. Individuals of the same size (1-2 cm, batch 4 and 5) and of the whole dreissenid field assemblage (batch 5) were compared to each other. The same sized individuals did not differ significantly in size (Mann-Whitney $U$ test: $\mathrm{U}=1224.00, \mathrm{~N} 1=53, \mathrm{~N} 2=54, P=0.190)$.

The relationship between the attachment strength and the byssal morphology was assessed by measuring the width and number of byssal threads for individuals of the whole dreissenid field assemblage. The byssal threads were collected by carefully cutting them from the individual as close as possible to the byssal gland and/or by picking the remaining ones from the substrate and were stored on $96 \%$ ethanol. The width of the collected byssal threads was measured using a
Dino-Light AM7013MZT digital microscope and the program DinoCapture 2.0 version 1.5.27.B. The width in the middle of each byssal thread was measured in $\mu \mathrm{m}$ at a magnification of 250x. On average 25 byssal threads were measured per individual and these values were used to calculate the average width of their byssal threads. Furthermore, the number of byssal threads was counted for field experiment mussels, which detached at the byssal gland in the mussels' foot, as this represented the only detachment type where all byssal threads could certainly be accounted for.

\section{Detachment location}

The detachment location of the byssal threads was determined by distinguishing between three categories: (1) plaques detachment: mostly due to the detachment of adhesive plaques or glue from the substrate, (2) byssal thread detachment: mostly due to the rupture of the byssal threads, (3) stem detachment: the rupture of the stem from the byssal gland, causing the entire byssal mass to be separated from the mussel. The difference between detachment locations was assessed between both species for batch 4 and 5 . Within each species we additionally assessed whether there was a relationship between the detachment location and their attachment strength (batch 5).

\section{Statistical analyses}

To assess the effects of byssal morphology traits on the attachment strength, a general linear model was constructed by backwards stepwise selection. The dependent variable "attachment strength" and explanatory variables "species", "shell length", "byssus width", "byssus count" and all their first order interactions were included in the initial model. Backwards stepwise model selection led to the exclusion of all non-significant first order interaction effects and the byssal thread counts. We tested whether adding tank as a random factor would improve model fit by comparing model fit parameters. However, the models with this random factor did not lead to a significantly better model fit. Therefore, we chose to use the least complex model without random factors. To assess the linear interdependence of both byssal thread traits (width and count), a Pearson correlation test was performed. A Spearman rank correlation test was performed to check for a linear correlation 

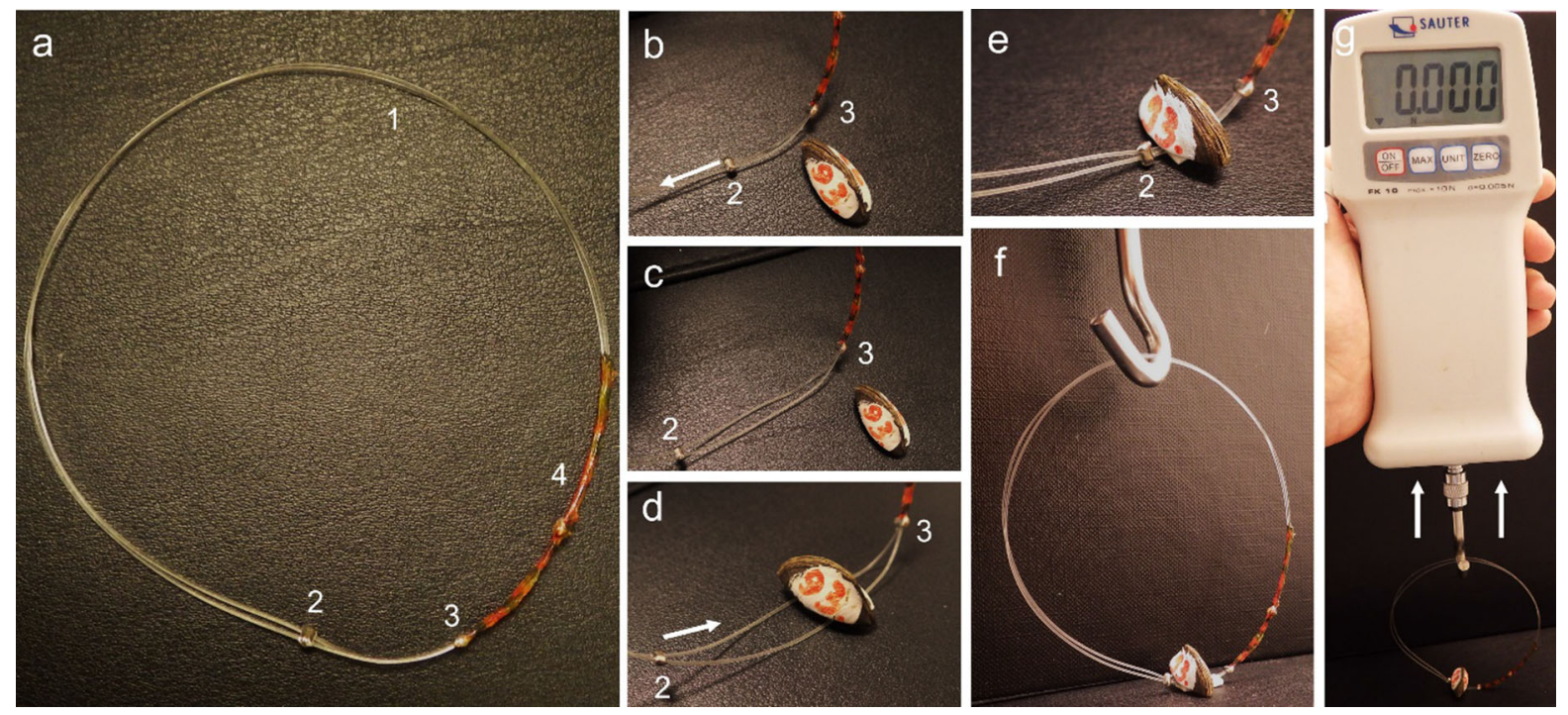

Fig. 2 The harness of fishing wire and Sauter FK10 digital force gauge used to measure the attachment strength of dreissenids. Panel a gives an overview of the harness with (1) two fishing wire loops, (2) a movable aluminium crimp, (3) a fixed

between the shell size, byssal thread width and count for both species separately.

Zooming in on the interaction of the shell length and attachment strength, a general linear model was assessed with shell length as a continuous variable. To assess whether the frequently selected shell size range $(1-2 \mathrm{~cm})$ in laboratory experiments had the same outcome regarding the species displaying the strongest attachment, a comparison was made with the complete dreissenid shell size range found in the field. We compared three types of attachment strength experiments: (1) same sized individuals in the laboratory $(1-2 \mathrm{~cm})$, (2) same sized individuals in the field (1-2 cm), (3) the whole dreissenid field assemblage. A general linear model with dependent variable "attachment strength" and explaining factors "species", "experiment type" and their first order interaction term was constructed. All assumptions for the use of a general linear model were met. Additionally, a Tukey HSD test was conducted as a post-hoc test for this general linear model.

A one-tailed Chi-square $\left(\chi^{2}\right)$ test was used to test whether the attachment rate was affected by species, species assemblage and light regime. This one-tailed Chi-square test was also used to assess whether there was a difference in detachment location of the byssal threads for both species. Finally, a Kruskal-Wallis aluminium crimp, and (4) the red and black area where both loops are glued together. The movable aluminium crimp (2) can be slid back and forward (panel $\mathbf{b}-\mathbf{e}$ ) to secure the mussel while detaching it from the substrate (panel $\mathbf{f}-\mathbf{g}$ )

rank-sum test was performed to check whether there was a link between the detachment location and the measured attachment strength. All analyses were performed using the software $\mathrm{R}$ (version 3.6.2) with a statistical significance level of $\alpha<0.05$.

\section{Results}

Attachment rate

The statistical test used, the test statistics, degrees of freedom and the P-values are represented in Tables 1 and 2. Combining the attachment rate for all batches (1-4), D. polymorpha individuals (85\%) attached significantly more often than $D$. bugensis individuals (76\%) to the substrate ( $P=0.013$; Table 1a, Fig. 3$)$. We found this pattern in three out of four measured batches (1-3). Additionally, we conducted a separate attachment analysis of batch 4 , as this batch had an opposite result with significantly more $D$. bugensis attaching to the tank wall (Chi-square test: $\chi^{2}=5.76$, d.f. $=1, P=0.016$; Fig. 3 ).

When comparing syntopic and allotopic populations there was no significant difference recorded in attachment rate either for D. polymorpha $(P=0.608)$ nor for $D$. bugensis $(P=0.058$; Table $1 b)$. 
Table 1 The relative number or mean with standard deviation, minimum and maximum values for the attachment rate and detachment location of Dreissena bugensis and D. polymorpha. The relative numbers were indicated in $\%$ and attachment strength values were indicated in Newtons $(\mathrm{N})$. The results of various experiments were statistically tested with a KruskalWallis rank-sum test $(\mathrm{K})$ or Chi-squared test $\left(\chi^{2}\right)$. Significant results were indicated with an asterisk symbol $(*)$

Experiment

Relative number or mean

( \pm SD)-minimum-maximum
Statistical test

\section{Attachment rate}

(a) Species

D. bugensis

D. polymorpha

(b) Syntopic versus allotopic populations

D. bugensis

D. polymorpha

(c) Light regime

D. bugensis

D. polymorpha

\section{Detachment location}

(d) Field experiment for both species

$\begin{array}{lll}\text { Byssal threads } & \text { D. bugensis } & 43 \% \\ \text { Adhesive plaques } & \text { D. polymorpha } & 61 \% \\ & \text { D. bugensis } & 38 \% \\ \text { Stem } & \text { D. polymorpha } & 33 \% \\ & \text { D. bugensis } & 19 \% \\ & \text { D. polymorpha } & 5 \%\end{array}$

(e) Laboratory versus field experiment for

D. bugensis

Byssal threads

Adhesive plaques

Stem

(f) Laboratory versus field experiment for D. polymorpha
Byssal threads

Adhesive plaques

Stem

\section{Detachment location and strength}

(g) Species-D. bugensis

Byssal threads

Adhesive plaques

Stem

(h) Species-D. polymorpha

Byssal threads

Adhesive plaques

Stem
$76 \%$

$85 \%$

Syntopic $=55 \%$, Allotopic $=78 \%$

Syntopic $=98 \%$, Allotopic $=93 \%$

Light $=75 \%$, Dark $=55 \%$

Light $=95 \%$, Dark $=100 \%$

$43 \%$

$61 \%$

$38 \%$

$33 \%$

$19 \%$

$5 \%$

Laboratory $=7 \%$, Field $=43 \%$

Laboratory $=17 \%$, Field $=38 \%$

Laboratory $=76 \%$, Field $=19 \%$

Laboratory $=64 \%$, Field $=61 \%$

Laboratory $=33 \%$, Field $=33 \%$
Laboratory $=3 \%$, Field $=5 \%$ $\chi^{2}=6.20$, d.f. $=1, P=0.013 *$

$\chi^{2}=3.58$, d.f. $=1, P=0.058$

$\chi^{2}=0.26$, d.f. $=1, P=0.608$

$\chi^{2}=0.99$, d.f. $=1, P=0.320$

$\chi^{2}<0.001$, d.f. $=1, P=1.000$

$\chi^{2}=4.70$, d.f. $=1, P=0.031 *$

$\chi^{2}=0.30$, d.f. $=1, P=0.617$

$\chi^{2}=5.30$, d.f. $=1, P=0.021 *$

$\chi^{2}=18.50$, d.f. $=1, P<0.001 *$

$\chi^{2}=8.90$, d.f. $=1, P=0.003^{*}$

$\chi^{2}=4.50$, d.f. $=1, P=0.035^{*}$

$\chi^{2}=0.03$, d.f. $=1, P=0.866$

$\chi^{2}<0.001$, d.f. $=1, P=1.000$

$\chi^{2}=0.17$, d.f. $=1, P=0.677$
The light regime had no significant effect on either D. polymorpha and D. bugensis $(P=1.000$, $P=0.320$, respectively; Table 1c, Online Resource 1).
$5.01( \pm 2.37)-0.01-10.00 \mathrm{~N}$
$4.88( \pm 3.57)-0.72-14.00 \mathrm{~N}$
$8.95( \pm 4.41)-2.49-18.00 \mathrm{~N}$

$3.22( \pm 2.39)-0.12-9.15 \mathrm{~N}$

$3.18( \pm 2.26)-0.17-8.99 \mathrm{~N}$ $1.99( \pm 1.45)-0.93-4.08 \mathrm{~N}$
$K=12.40$, d.f. $=2, P=0.002 *$

$K=0.70$, d.f. $=2, P=0.855$

\section{Attachment strength}

The three attachment strength experiments (Same sized individuals in the laboratory, same sized individuals in the field and the whole dreissenid field 
Table 2 The mean with standard deviation, minimum and maximum values for the attachment strength and byssal thread morphology of Dreissena bugensis and D. polymorpha. The attachment strength values were indicated in Newtons $(\mathrm{N})$. The attachment strength in relation to size indicates the shell size of each species (in $\mathrm{mm}$ ). The byssal thread morphology includes the byssal thread width (in $\mu \mathrm{m}$ ) and count. The results of various experiments were statistically tested with a Linear model $(\operatorname{Lm}(\mathrm{t}))$, Tukey's HSD post-hoc test $\left(\mathrm{T}_{\mathrm{HSD}}\right)$, Pearson correlation test (r) or a Spearman rank correlation test $(\mathrm{S})$. Significant results were indicated with an asterisk symbol (*)

Experiment

Mean ( \pm SD)-minimum-

maximum

\section{Attachment strength}

(a) Difference between three setups

Lab same size vs field same size vs field whole assemblage

(b) Laboratory experiment (same size: $1-2 \mathrm{~cm}$ )-linear model $\mathrm{df}(5,397)$
D. bugensis
$0.81( \pm 0.58)-0.05-2.05 \mathrm{~N}$
D. polymorpha
$1.12( \pm 0.68)-0.10-2.94 \mathrm{~N}$

(c) Field experiment (same size: $1-2 \mathrm{~cm}$ )-linear model $\mathrm{df}(5,397)$
D. bugensis
$3.67( \pm 2.26)-0.01-10.00 \mathrm{~N}$
D. polymorpha
4.19 ( \pm 2.07$)-0.17-9.15 \mathrm{~N}$
$T_{H S D}: P=1.000$

$\operatorname{Lm}(t)=33.55$, d.f. $=5,397, P=0.002 *$

Adjusted $R^{2}=0.288$

$T_{H S D}: P=0.972$

(d) Field experiment-linear model df(5, 397) (whole dreissenid assemblage; D. bugensis $0.4-3.2 \mathrm{~cm}$, D. polymorpha $0.4-2.0 \mathrm{~cm}$ )
D. bugensis
$4.73( \pm 3.80)-0.01-18.00 \mathrm{~N}$
$T_{H S D}: P<0.001^{*}$
D. polymorpha
$3.13( \pm 2.40)-0.12-9.46 \mathrm{~N}$

Attachment strength in relation to shell size

(e) Dreissenid shell size (whole dreissenid field assemblage)
D. bugensis
$17.57( \pm 6.55)-4.54-31.94 \mathrm{~mm}$
$N A$
D. polymorpha
$12.70( \pm 3.32)-4.37-20.64 \mathrm{~mm}$
$N A$

(f) Attachment strength in relation to shell size (whole dreissenid field assemblage)
D. bugensis
$4.73( \pm 3.80)-0.01-18.00 \mathrm{~mm}$
D. polymorpha
$3.13( \pm 2.40)-0.12-9.46 \mathrm{~mm}$

$\operatorname{Lm}(t)=11.14$, d.f. $=1,196, P=0.001^{*}$

\section{Byssal thread morphology}

(g) Byssal thread morphology correlation

Byssal thread width

NA

Byssal thread count

NA

(h) Byssal thread width-linear model $\mathrm{df}(3,36)$
D. bugensis
D. polymorpha

Correlation size and byssal width $D$. bugensis

Correlation size and byssal width $D$. polymorpha

$$
\begin{aligned}
& 56.77( \pm 13.33)-33.89-86.35 \mu \mathrm{m} \\
& 35.13( \pm 4.60)-26.25-43.33 \mu \mathrm{m} \\
& \text { NA }
\end{aligned}
$$

NA

(i) Byssal thread count

D. bugensis

D. polymorpha

Correlation size and byssal count $D$. bugensis

$235( \pm 136)-32-570$

116 ( \pm 72$)-40-290$

NA

Correlation size and byssal count $D$. polymorpha
NA
Adjusted $R^{2}=0.049$

$r=0.52$, d.f. $=17, P=0.024 *$

$\operatorname{Lm}(t)=15.93$, d.f. $=1, P<0.001^{*}$

Adjusted $R^{2}=0.466$

$\mathrm{S}=3327.00, \mathrm{~N}=32, P=0.027$ *

rho $=0.390$

$\mathrm{S}=2568.10, \mathrm{~N}=26, P=0.553$

rho $=0.122$

Sample size too small

$\mathrm{S}=339.13, \mathrm{~N}=19, P<0.001 *$

rho $=0.703$

$\mathrm{S}=1219.10, \mathrm{~N}=18, P=0.301$

rho $=-0.258$ 
Fig. 3 The attachment rate and numbers of (un)attached dreissenids in the laboratory experiment for Dreissena bugensis and D. polymorpha of each batch

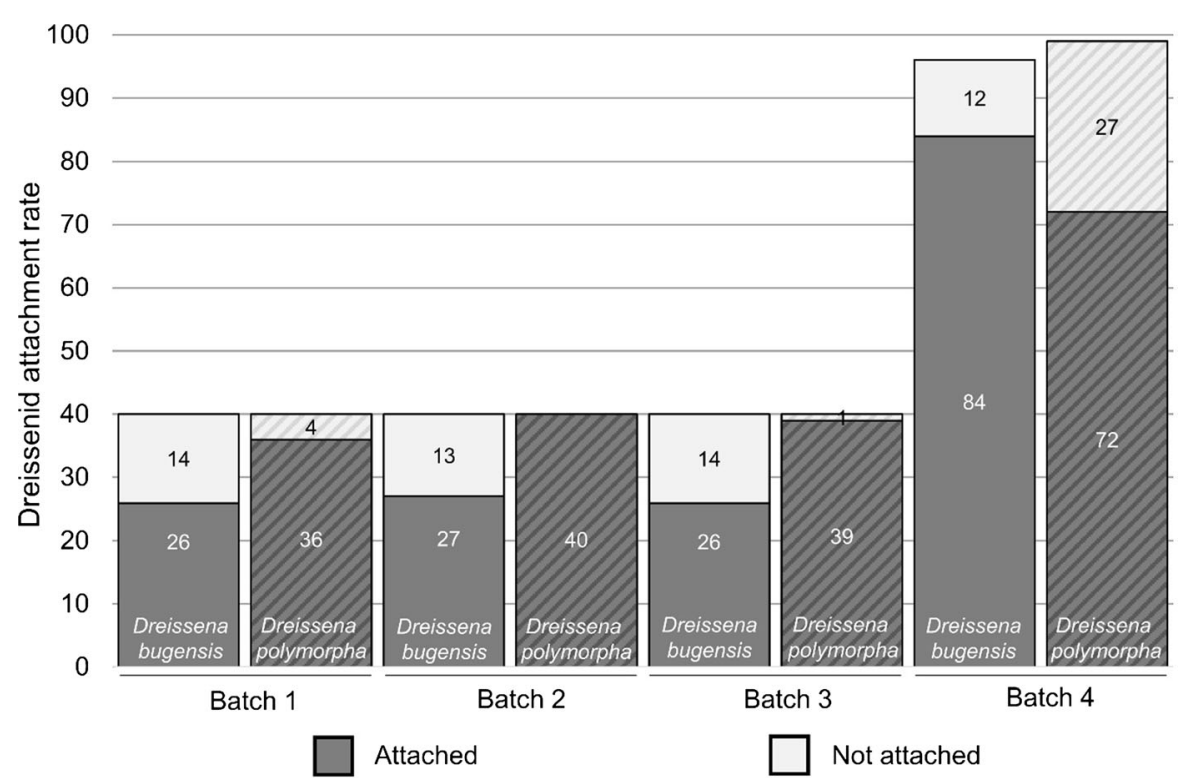

between both species $(P=0.972$; Table $2 b)$. Additionally, no significant difference was found for individuals of the 1-2 $\mathrm{cm}$ size class during the field experiment ( $P=1.000$; Table $2 \mathrm{c})$. When assessing the whole dreissenid field assemblage with individuals of all sizes (D. bugensis $0.4-3.2 \mathrm{~cm}, D$. polymorpha $0.4-2.0 \mathrm{~cm}$ ), the attachment strength of $D$. bugensis mussels was significantly higher than the attachment strength of $D$. polymorpha mussels $(P<0.001$; Table 2d). For both species an approximately four times greater attachment strength was found for individuals on fouling plates in the field, in comparison to individuals that attached themselves to the polyethene tanks within the laboratory setup (MannWhitney U test: D. bugensis: $\mathrm{U}=3323.00$, d.f. $=44$, $P<0.001$; D. polymorpha: $\mathrm{U}=3404.00$, d.f. $=49$, $P<0.001)$.

The attachment strength of dreissenids in general was positively related to their shell size (Fig. 4). Larger dreissenids attached significantly stronger to the substrate $(P=0.001$; Table $2 \mathrm{f})$. This relation between the shell size and attachment strength was stronger for D. polymorpha as the increase in attachment strength with shell size was stronger for this species (Fig. 4).

Byssal threads

The byssal thread width of $D$. bugensis was found to be significantly different and nearly double the width of $D$. 
polymorpha during the field experiment $(P<0.001$; Table $2 \mathrm{~h}$ ). The byssal thread width and count were positively correlated to each other $(P=0.024$; Table 2g). Therefore, the effect of byssal thread morphology (width and count) should not be analysed separately. The byssal thread count had a low sample size ( $\mathrm{N}=4$ for $D$. polymorpha). To obtain results for the byssal thread count we rely on the correlated byssal thread width results. The positive correlation between the byssal thread width and count indicate a similar result for both byssal morphology traits. Assessing the average byssal counts we found about twice as many byssal treads for $D$. bugensis in comparison to $D$. polymorpha (Table $2 \mathrm{i}$ ). The byssal thread width was positively correlated to the shell size for D. bugensis, while there was no correlation found for D. polymorpha ( $P=0.027, P=0.553$, respectively; Table $2 \mathrm{~h}$ ). The number of byssal threads was positively correlated to the shell size for $D$. bugensis, while there was no correlation found for $D$. polymorpha $(P<0.001, P=0.301$, respectively; Table $2 \mathrm{i}$ ).

\section{Detachment location}

Both species detached at the plaques, stem or by rupture of the byssal threads when they were pulled away from the SETL plate (Table 1d; Online Resource 2). At the end of the field experiment, D. bugensis had no significant difference between the detachments at the adhesive plaques ( $38 \%$ of the detachments) and by the rupture of byssal threads (43\%) (Chi-square test: $\chi^{2}=0.20$, d.f. $=1, P=0.642$ ). The stem detachment happened significantly less often than the adhesive plaque or byssal thread rupture (Chi-square test: $\chi^{2}=7.31, \quad$ d.f. $=1, \quad P=0.007$ and $\chi^{2}=10.91$, d.f. $=1, P=0.001$, respectively). Dreissena polymorpha detached in most cases due to the rupture of the byssal threads ( $61 \%$ of the detachments). The byssal thread rupture happened significantly more often than the adhesive plaque or stem detachment (Chi-square test: $\chi^{2}=10.70$, d.f. $\left.=1, P=0.001\right)$. Dreissena polymorpha detached significantly more often because of the rupture of byssal threads than $D$. bugensis did $(P=0.031$; Table 1d). Dreissena bugensis, on the other hand, detached about four times more often because of the rupture of the stem than $D$. polymorpha $\operatorname{did}(P=0.021)$. For $D$. polymorpha there was no significant difference between detachment locations found for individuals originating from the field experiment and controlled laboratory conditions (Table 1f). However, D. bugensis individuals in controlled laboratory conditions detached about 6 times more often by rupture of the byssal threads $(P<0.001)$, about four times less by rupture of the stem $(P=0.035)$ and about two times less by the detachment of the adhesive plaques $(P=0.003)$ than those who settled during the field experiment (Table 1e).

It took nearly double the amount of force to detach D. bugensis individuals experiencing stem failure from the substrate compared to individuals detaching at the adhesive plaques or the byssal threads $(P=0.002$; Table 1g, Online Resource 3). There was no significant difference in attachment strength between individuals detaching at the adhesive plaques or by rupture of the byssal threads. For D. polymorpha no significant differences in attachment strength were found for the different detachment locations ( $P=0.855$; Table 1h, Online Resource 3). During the course of the experiment, entire byssal masses were found free floating in the tanks for both species.

\section{Discussion}

Attachment strength and byssal thread morphology

This study presents a first time comparison between the attachment strength of two invasive freshwater mussel species in laboratory and field experiments. The comparisons of individuals of the same size in both the laboratory and field experiment did not result in significant differences in attachment strength between both species, contrary to our hypothesis. Based on previous studies, we would expect $D$. polymorpha to have a greater attachment strength in this situation (Peyer et al. 2009; Grutters et al. 2012; Collas et al. 2018). However, judging from the results obtained by Balogh et al. (2019), laboratory kept individuals with a size between $1-2 \mathrm{~cm}$ and an attachment duration of about one week, would not have a clear difference in attachment strength for both species. In accordance with our hypothesis, attachment strength was found to be positively related to mussel size (Table 2; Fig. 4) as also found by Kobak (2006) and Balogh et al. (2019). The curve in Fig. 4 clearly indicates why the attachment strength differed significantly between both species when assessing 
individuals of the whole size range, and why no significant difference was found when assessing individuals with a shell size between 1 and $2 \mathrm{~cm}$. Dreissena polymorpha individuals displayed a stronger increase of attachment strength per unit length (though starting from a lower initial attachment strength for smaller individuals), resulting in a stronger adhesion for larger specimens of the same size as D. bugensis. However, D. bugensis grows faster and becomes larger than D. polymorpha individuals do (D'Hont et al. 2018). Therefore, the large D. bugensis individuals end up with a greater attachment strength than $D$. polymorpha individuals of the same age. Balogh et al. (2019) found a similar, however, reversed pattern, as D. bugensis individuals displayed a stronger increase of attachment strength per unit length. Since dreissenids attach to hard substratum using byssal threads, factors affecting their byssogenesis might impact their attachment strength. The byssogenesis is influenced by multiple environmental cues, such as temperature, salinity, dissolved oxygen, light, hydrodynamics, adhesion surface and season (Grutters et al. 2012; Balogh et al. 2019). Our results were obtained from field deployed fouling plates and individuals who had 9 to 21 months to attach themselves to the fouling plates. We know the possible duration of attachment as the two settlement events during this study happened respectively 9 and 21 months prior to our measurements. These plates were exposed to various seasons, temperatures and currents. Moreover, Dutch river deltas and upstream reaches of the rivers Rhine and Meuse are intensively used for navigation, causing ship-induced changes in flow velocity (Koopman et al. 2018). Adaptation of collected dreissenids to harsh environmental conditions could cause discrepancy with results of Balogh et al. (2019), as they tested randomly collected mussels kept under constant laboratory conditions for a maximum of one month.

Considering shell size affected the attachment strength, the size of individuals was taken into account when comparing results of our attachment experiments. Individuals of both species of in dreissenid field assemblage differ in size as D. bugensis $(0.4-3.2 \mathrm{~cm})$ grows faster and larger than $D$. polymorpha $(0.4-2.0 \mathrm{~cm})$ (D'Hont et al. 2018). The attachment strength of the larger D. bugensis was significantly greater than that of smaller $D$. polymorpha individuals. Larger individuals are probably more affected by currents and are more visible for predators (Hunt and Scheibling 2001; Balogh et al. 2019). The individuals involved in the field experiment were all collected in front of the sluice of the ferry harbour to the island Tiengemeten, so they are regularly exposed to strong ship-induced currents. Moreover, D. bugensis individuals have a strong clustering behaviour causing the larger and older individuals to carry conspecifics on their shell (D'Hont et al. 2018; Jermacz et al. 2021). We can hypothesise that the larger D. bugensis individuals had to compensate for these circumstances by investing in a higher attachment strength. These larger mussels might secrete mechanically superior and thicker byssal threads compared to smaller individuals, as has already been found in Mytilus galloprovincialis (Babarro et al. 2008; Babarro and Carrington 2013). In accordance with our hypothesis, our data indicate that the byssal threads of $D$. bugensis were nearly twice as thick as those of $D$. polymorpha. Likewise, the number of byssal threads was twice as high for D. bugensis. Additionally, we found a positive correlation between the byssal thread width and count and the shell size of $D$. bugensis. This relates to the significantly greater attachment strength observed for the larger D. bugensis. It is known that the number and thickness of byssal threads have a positive impact on the attachment strength (Bell and Gosline 1997). Another possible explanation for the higher attachment strength for D. bugensis during the field experiment might be a difference in physical condition between both species (cf. Balogh et al. 2019). If $D$. bugensis has a better physical condition due to favourable environmental parameters (e.g. light, temperature, salinity) for this species over D. polymorpha, they might be able to spend more energy on their attachment to the substrate. Nevertheless, the significantly greater attachment strength makes $D$. bugensis a stronger competitor during disturbances than $D$. polymorpha individuals of the same age.

Comparing the mean attachment strength during the laboratory experiment for D. polymorpha $(1.12 \mathrm{~N})$ and $D$. bugensis $(0.81 \mathrm{~N})$ to the results from Peyer et al. (2009) for respectively $D$. polymorpha $(1.13 \mathrm{~N})$ and D. bugensis $(0.97 \mathrm{~N})$, we found that these measurements do not differ from one another. The experiment of Peyer et al. (2009) was run for two months while ours lasted for seven days. This would thus suggest that the attachment strength of both species does not increase that much after seven days. 
Ackerman et al. (1996) conducted an attachment experiment in the field for D. polymorpha individuals and found an attachment strength between 0.35-1.60 N depending on the substrate type. During our field experiment, we found a mean attachment strength of $4.16 \mathrm{~N}$ for $D$. polymorpha and $3.67 \mathrm{~N}$ for $D$. bugensis for individuals with a similar size $(1-2 \mathrm{~cm})$ as reported by Ackerman et al. (1996). The attachment strength obtained in the present study was thus more than two times higher. This might be due to the experimental setup. Ackerman et al. (1996) kept their substrate containing the mussels in a laboratory setup for one month after retrieval from the field before conducting the measurements. These artificial environmental conditions might have caused the dreissenids to start looking for a new environment by voluntary detaching and reattaching themselves within one-month time. The present study measured the attachment strength of the dreissenids immediately after recovery from the field assuring their attachment strength did not change.

The attachment strength for both dreissenids was about four times higher during the field experiment in comparison to the laboratory experiment. In the field experiment, we used polyvinylchloride (PVC) plates especially sanded to increase the attachment, while the laboratory experiment used smooth polyethene tanks. The difference in roughness of the substrate most likely had an effect on the attachment strength of both species (Ackerman et al. 1996). An alternative explanation may be the duration of the attachment period, as dreissenids in the field experiment may have had a longer attachment period. Balogh et al. (2019) indicated that attachment strength still slightly increases after seven days for both $D$. bugensis and $D$. polymorpha. Moreover, unlike the laboratory experiment, individuals in the field experiment were potentially exposed to currents due to their location in front of the sluice. The correlation between attachment strength and currents has already been proven for blue mussels (Mytilus edulis) and Mediterranean mussels (Mytilus galloprovincialis) (Hunt and Scheibling 2001; Lachance et al. 2008; Balogh et al. 2019).

\section{Attachment rate}

In total $76 \%$ of D. bugensis and $85 \%$ of D. polymorpha attached to the substrate during the laboratory experiment (Table 1). Thus, D. polymorpha attached significantly more often to the hard substrate in controlled laboratory conditions than D. bugensis, which corresponds to previous findings (Collas et al. 2018). This was the case for three out of four experiments (Fig. 3). Batch 4, however, had an opposite result with more D. bugensis attaching to the substrate. The number of individuals in each tank for this batch was more than two times higher (Fig. 1). This might be one of the reasons causing the observed difference for batch 4 . The attachment rate of a species might be related to their search for an optimal settlement environment. D'Hont et al. (2021) found that more $D$. bugensis individuals than $D$. polymorpha individuals moved around the tanks during the laboratory experiment, instead of settling down. Dreissenids usually move for a short period, i.e. a few minutes up to maximum of three hours (D'Hont et al. 2021). Furthermore, changes in the environment due to, for example, intense rainfall will generally take place within a short timeframe as well (minutes to a few hours). In these extreme cases it may be important that an individual can quickly escape the resulting poor environmental conditions. As the laboratory setup likely resembled suboptimal environmental conditions, this would indicate that D. bugensis individuals were actively seeking a better environment. This trait would give $D$. bugensis a benefit over $D$. polymorpha possibly explaining the dominance shift between these species.

The co-occurrence of both dreissenid species is known to affect their densities, as a higher number of $D$. bugensis individuals settled when $D$. polymorpha individuals were already present on the substrate (D'Hont et al. 2018). The presence of individuals of the same species positively affects the attachment rate, while injured conspecifics reduced the byssal attachment as a reaction to the presence of potential predators (Kobak 2001; Czarnołęski et al. 2010). In our study, however, the presence or absence of the other dreissenid species had no significant effect on the dreissenids' attachment rate (Table 1).

The presence or absence of light in the present study had no significant effect on the attachment of $D$. polymorpha or D. bugensis individuals, which corresponds to the results of Grutters et al. (2012). Dreissena polymorpha is known to have a preference for settlement in dark environments and mussels in illuminated environments changed their initial sites 
less often than those kept in darkness (Kobak 2006; Kobak and Nowacki 2007; Kobak et al. 2009). The unfavourable environmental conditions created during our laboratory setup may be strong enough to counteract the effect of light on dreissenids' settlement. This might also have been the case in the study of Grutters et al. (2012). The sample size and replication rate for this experiment were relatively low as well ( $\mathrm{N}=20$ for each treatment, light and dark). This low sample size might have caused possible significant trends to get lost. Online Resource 1 indicates a trend in which light exposed D. bugensis individuals had a higher attachment rate than individuals kept in a dark environment. The in depth assessment of this interaction would be recommended for future studies.

\section{Detachment location}

Dreissena polymorpha individuals detached $20 \%$ more often because of the rupture of their byssal threads than D. bugensis individuals did (Table 1; Online Resource 2). This would mean that the $D$. bugensis byssal threads are stronger than the byssal threads of $D$. polymorpha, which corresponds to the attachment strength related to a detachment by the rupture of the byssal threads for both species (Table 1; Online Resource 3). Dreissena bugensis, on the other hand, displayed four times more often stem or gland detachment than D. polymorpha. This type of detachment is relatively uncommon for $D$. polymorpha (Dormon et al. 1997). In our study, stem detachments of D. bugensis were associated with relatively high attachment strengths and the presence of relatively high byssal thread counts. Only few D. polymorpha individuals showed stem ruptures, however, these cases were not associated with a higher attachment strength. Information on the detachment location of either species under natural conditions is scarce. A remarkable observation were the free floating byssal masses for both species. The common blue mussel (Mytilus edulis) is known to detach its entire byssal mass, however, the underlying mechanisms are not yet well understood (Eckroat et al. 1993). Voluntary detachment is also known for D. polymorpha individuals (Kobak et al. 2009; Dzierżyńska-Białończyk et al. 2018). Apart from that, not much is known on the voluntarily detachment of dreissenids, as most studies only assessed forced detachment of both species (Eckroat et al. 1993; Kobak et al. 2009). Especially a comparison between the voluntarily detachment of both species is missing. This would therefore be recommended for future studies. Overall, our results support the hypothesis that differential attachmentdetachment traits might to some degree be one of the contributing drivers of the ongoing dominance shift between $D$. polymorpha and D. bugensis.

\section{Conclusions}

The goal of this study was to assess whether the attachment of dreissenids explained, at least for some degree, the ongoing dominance shift between $D$. bugensis and $D$. polymorpha. Shell size and attachment strength were positively correlated in both species. Dreissena polymorpha individuals showed a faster increment of attachment strength per unit length, resulting in a stronger adhesion for larger specimens of the same size as D. bugensis. However, $D$. bugensis grows faster and becomes larger than $D$. polymorpha. Therefore, for field deployed individuals of the whole available size range, the attachment strength in D. bugensis was significantly higher in comparison to $D$. polymorpha. This higher attachment strength can at least partially be explained by the byssal thread morphology as these byssal threads were about two times thicker for D. bugensis, which also correlated to a higher number of byssal threads. Additionally, D. polymorpha individuals detached significantly more often because of the rupture of their byssal threads than $D$. bugensis individuals did. This indicates that the byssal threads of $D$. bugensis are stronger than the byssal threads of $D$. polymorpha. These attachment traits likely give D. bugensis mussels an advantage over $D$. polymorpha mussels within a dreissenid field assemblage when it comes to withstanding currents and predators. Additionally, $D$. bugensis had a significantly lower attachment rate. This may be explained by a higher number of $D$. bugensis individuals searching for the optimal habitat, as the laboratory setup likely resembled suboptimal environmental conditions. The results support our hypothesis that the differences in attachment-detachment traits might to some degree be one of the contributing drivers of the ongoing dominance shift between both species. 
Acknowledgements The authors would like to thank the European Union's Horizon 2020 research and innovation programme and the Innovative Training Network 2015-2019 Drivers of Pontocaspian Biodiversity Rise and Demise (PRIDE) under the Marie Sklodowska-Curie Grant Agreement No 642973 of the European Commission for funding and supporting this research. We thank Naveen Parthiban and two anonymous reviewers for their critical comments and suggestions to improve this paper. We thank the GiMaRIS team for their assistance during the practical part of this research. We acknowledge Mr Veldhoen, Mr Kruithof and ferry service 'de Hoeksche Vaart' for facilitating fieldwork in Numansdorp and Tiengemeten. Finally, special thanks go to Martijn Van Roie for his support throughout this research.

Author contributions All authors contributed to the study conception and design. Material preparation, data collection and analysis were performed by AD. The first draft of the manuscript was written by $\mathrm{AD}$ and all authors commented on subsequent versions of the manuscript. All authors read and approved the final manuscript.

Funding This research was funded by the Marie SklodowskaCurie Grant Agreement No 642973 of the European Commission.

Availability of data and material Data available from the DANS-EASY digital repository https://doi.org/10.17026/dansxzn-aen9 (D'Hont A, Gittenberger A, Hendriks AJ, Leuven RSEW, 2020).

\section{Declarations}

Conflict of interest The authors declare that they have no conflict of interest.

Ethics approval Our manuscript adheres to publisher's Ethical Guidelines.

Consent for publication All authors agreed with the content and they all gave explicit consent to submit.

Open Access This article is licensed under a Creative Commons Attribution 4.0 International License, which permits use, sharing, adaptation, distribution and reproduction in any medium or format, as long as you give appropriate credit to the original author(s) and the source, provide a link to the Creative Commons licence, and indicate if changes were made. The images or other third party material in this article are included in the article's Creative Commons licence, unless indicated otherwise in a credit line to the material. If material is not included in the article's Creative Commons licence and your intended use is not permitted by statutory regulation or exceeds the permitted use, you will need to obtain permission directly from the copyright holder. To view a copy of this licence, visit http://creativecommons.org/licenses/by/4.0/.

\section{References}

Ackerman JD, Cottrell CM, Ethier CR, Allen DG, Spelt JK (1996) Attachment strength of zebra mussels on natural, polymeric, and metallic materials. J Environ Eng 122(2):141-148. https://doi.org/10.1061/(asce)07339372(1996)122:2(141)

Balogh C, Serfőző Z, Bij de Vaate A, Noordhuis R, Kobak J (2019) Biometry, shell resistance and attachment of zebra and quagga mussels at the beginning of their co-existence in large European lakes. J Great Lakes Res 45(4):777-787. https://doi.org/10.1016/j.jglr.2019.05.011

Babarro JM, Carrington E (2013) Attachment strength of the mussel Mytilus galloprovincialis: effect of habitat and body size. J Exp Mar Biol Ecol 443:188-196. https://doi. org/10.1016/j.jembe.2013.02.035

Babarro JM, Reiriz MJF, Labarta U (2008) Secretion of byssal threads and attachment strength of Mytilus galloprovincialis: the influence of size and food availability. J Mar Biol Assoc U K 88(4):783-791. https://doi.org/10.1017/ s0025315408001367

Bell EC, Gosline JM (1997) Strategies for life in flow: tenacity, morphometry, and probability of dislodgment of two Mytilus species. Mar Ecol Prog Ser 159:197-208. https:// doi.org/10.3354/meps159197

Bódis E, Tóth B, Sousa R (2014) Impact of Dreissena fouling on the physiological condition of native and invasive bivalves: interspecific and temporal variations. Biol Invasions 16(7):1373-1386. https://doi.org/10.1007/s10530-013$0575-\mathrm{z}$

Claxton WT, Mackie GL (1998) Seasonal and depth variations in gametogenesis and spawning of Dreissena polymorpha and Dreissena bugensis in eastern Lake Erie. Can J Zool 76:2010-2019. https://doi.org/10.1139/z98-150

Collas FPL, Karatayev AY, Burlakova LE, Leuven RSEW (2018) Detachment rates of dreissenid mussels after boat hull-mediated overland dispersal. Hydrobiologia 810(1):77-84. https://doi.org/10.1007/s10750-016-3072-4

Czarnołęski M, Müller T, Adamus K, Ogorzelska G, Sog M (2010) Injured conspecifics alter mobility and byssus production in zebra mussels Dreissena polymorpha. Fundam Appl Limnol Archiv für Hydrobiologie 176(3):269-278. https://doi.org/10.1127/1863-9135/2010/0176-0269

D'Hont A, Gittenberger A, Hendriks AJ (2018) Leuven RSEW (2018) Drivers of dominance shifts between invasive Ponto-Caspian dreissenids Dreissena polymorpha (Pallas, 1771) and Dreissena rostriformis bugensis (Andrusov,1897). Aquat Invasions 13(4):449-462. https://doi. org/10.3391/ai.2018.13.4.03

D’Hont A, Gittenberger A, Hendriks AJ, Leuven RSEW (2021) Dreissenids' need for speed: mobility as a driver of the dominance shift between two invasive Ponto-Caspian mussel species. Aquatic Invasions 16(1):113-128. https:// doi.org/10.3391/ai.2021.16.1.08

Dzierżyńska-Białończyk A, Skrzypczak A, Kobak J (2018) Happy together? Avoidance of conspecifics by gregarious mussels. Curr Zool 64(1):53-61. https://doi.org/10.1093/ cz/zox022

Dormon JM, Coish C, Cottrell C, Allen DG, Spelt JK (1997) Modes of byssal failure in forced detachment of zebra 
mussels. J Environ Eng 123(9):933-938. https://doi.org/ 10.1061/(asce)0733-9372(1997)123:9(933)

Eckroat LR, Masteller EC, Shaffer JC, Steele LM (1993) The byssus of the zebra mussel (Dreissena polymorpha): morphology, byssal thread formation and detachment. In: Nalepa TF, Schloesser DW (eds) Zebra mussels: biology, impacts, and control. Lewis Publishers CRC Press, Boca Raton, pp 239-263

Gerstenberger SL, Mueting SA, Wong WH (2011) Veligers of invasive quagga mussels (Dreissena rostriformis bugensis, Andrusov 1897) in Lake Mead, Nevada-Arizona. J Shellfish Res 30:933-938. https://doi.org/10.2983/035.030. 0335

Ginn BK, Bolton R, Coulombe D, Fleischaker T, Yerex G (2018) Quantifying a shift in benthic dominance from zebra (Dreissena polymorpha) to quagga (Dreissena rostriformis bugensis) mussels in a large, inland lake. J Great Lakes Res 44(2):271-282. https://doi.org/10.1016/ j.jglr.2017.12.003

Gittenberger A, Wesdorp KH, Rensing M (2017) Biofouling as a transport vector of non-native marine species in the Dutch Delta, along the North Sea coast and in the Wadden Sea. GiMaRIS report 2017_03. Issued by Office for Risk Assessment and Research, Netherlands Food and Consumer Product Safety Authority, The Netherlands, p 48

Gonçalves V, Rebelo R, Gherardi F (2013) Fouling of invasive red swamp crayfish, Procambarus clarkii (Girard, 1852) by the zebra mussel, Dreissena polymorpha (Pallas, 1771) in Lake Trasimeno. Italy Aquat Invasions 8(1):117-120. https://doi.org/10.3391/ai.2013.8.1.14

Grutters BM, Verhofstad MJ, van der Velde G, Rajagopal S, Leuven RSEW (2012) A comparative study of byssogenesis on zebra and quagga mussels: the effects of water temperature, salinity and light-dark cycle. Biofouling 28(2):121-129. https://doi.org/10.1080/08927014.2012. 654779

Hines AH, Ruiz GM (2001) Marine invasive species and biodiversity of South Central Alaska. Prince William Sound Regional Citizen's Advisory Council Valdez, Anchorage, USA, p 75

Hunt HL, Scheibling RE (2001) Predicting wave dislodgment of mussels: variation in attachment strength with body size, habitat, and season. Mar Ecol Prog Ser 213:157-164. https://doi.org/10.3354/meps213157

Jermacz L, Balogh C, Kobak J (2021) Behavioural differences and interactions between two sessile bivalves forming mixed-species assemblages. Anim Behav 171:13-28. https://doi.org/10.1016/j.anbehav.2020.11.001

Karatayev AY, Burlakova LE, Mastitsky SE, Padilla DK, Mills EL (2011) Contrasting rates of spread of two congeners, Dreissena polymorpha and Dreissena rostriformis bugensis, at different spatial scales. J Shellfish Res 30(3):923-932. https://doi.org/10.2983/035.030.0334

Karatayev AY, Burlakova LE, Padilla DK (2014) General overview of zebra and quagga mussels: what we do and do not know. In: Nalepa TF, Schloesser DW (eds) Quagga and zebra mussels: biology, impacts, and control. Lewis Publishers, CRC Press, Taylor and Francis Group, Boca Raton, pp 695-703. https://doi.org/10.1201/b15437-53

Kobak J (2001) Light, gravity and conspecifics as cues to site selection and attachment behaviour of juvenile and adult
Dreissena polymorpha Pallas, 1771. J Molluscan Stud 67(2):183-189. https://doi.org/10.1093/mollus/67.2.183

Kobak J (2006) Factors influencing the attachment strength of Dreissena polymorpha (Bivalvia). Biofouling 22(3):141-150. https://doi.org/10.1080/ 08927010600691895

Kobak J (2013) Behavior of juvenile and adult zebra mussels (Dreissena polymorpha). In: Nalepa TF, Schloesser DW (eds) Quagga and zebra mussels: biology, impacts, and control. Lewis Publishers CRC Press, Taylor and Francis Group, Boca Raton, pp 331-344. https://doi.org/10.1201/ b15437-28

Kobak J, Nowacki P (2007) Light-related behaviour of the zebra mussel (Dreissena polymorpha, Bivalvia). Fundam Appl Limnol Archiv für Hydrobiologie 169(4):341-352. https:// doi.org/10.1127/1863-9135/2007/0169-0341

Kobak J, Poznańska M, Kakareko T (2009) Effect of attachment status and aggregation on the behaviour of the zebra mussel Dreissena polymorpha. J Molluscan Stud 75(2):119-126. https://doi.org/10.1093/mollus/eyn046

Koopman KR, Collas FPL, Breure AM, Lenders HJR, van der Velde G, Leuven RSEW (2018) Predicting effects of shipinduced changes in flow velocity on native and alien molluses in the littoral zone of lowland rivers. Aquat Invasions 13(4):481-490. https://doi.org/10.3391/ai.2018. 13.4.06

Lachance AA, Myrand B, Tremblay R, Koutitonsky V, Carrington E (2008) Biotic and abiotic factors influencing attachment strength of blue mussels Mytilus edulis in suspended culture. Aquat Biol 2(2):119-129. https://doi.org/ 10.3354/ab00041

Marescaux J, Boets P, Lorquet J, Sablon R, Van Doninck K, Beisel J-N (2015) Sympatric Dreissena species in the Meuse River: towards a dominance shift from zebra to quagga mussels. Aquat Invasions 10(3):287-298. https:// doi.org/10.3391/ai.2015.10.3.04

Matthews J, Van der Velde G, Bij de Vaate AB, Collas FPL, Koopman KR, Leuven RSEW (2014) Rapid range expansion of the invasive quagga mussel in relation to zebra mussel presence in The Netherlands and Western Europe. Biol Invasions 16(1):23-42. https://doi.org/10.1007/ s10530-013-0498-8

Metz O, Temmen A, von Oheimb K, Albrecht C, Schubert P, Wilke T (2018) Invader vs. invader: intra-and interspecific competition mechanisms in zebra and quagga mussels. Aquat Invasions 13(4):473-480. https://doi.org/10.3391/ ai.2018.13.4.05

Molloy DP, Bij de Vaate A, Wilke T, Giamberini L (2007) Discovery of Dreissena rostriformis bugensis (Andrusov 1897) in western Europe. Biol Invasions 9(7):871-874. https://doi.org/10.1007/s10530-006-9078-5

Naddafi R, Rudstam LG (2014) Predation on invasive zebra mussel, Dreissena polymorpha, by pumpkinseed sunfish, rusty crayfish, and round goby. Hydrobiologia 721(1):107-115. https://doi.org/10.1007/s10750-0131653-Z

Orlova MI, Therriault TW, Antonov PI, Shcherbina GK (2005) Invasion ecology of quagga mussels (Dreissena rostriformis bugensis): a review of evolutionary and phylogenetic impacts. Aquat Ecol 39(4):401-418. https://doi.org/ 10.1007/s10452-005-9010-6 
Peyer SM, McCarthy AJ, Lee CE (2009) Zebra mussels anchor byssal threads faster and tighter than quagga mussels in flow. J Exp Biol 212(13):2027-2036. https://doi.org/10. 1242/jeb.028688

Pimentel D, Zuniga R, Morrison D (2005) Update on the environmental and economic costs associated with alien-invasive species in the United States. Ecol Econ 52(3):273-288. https://doi.org/10.1016/j.ecolecon.2004. 10.002

Ram JL, Karim AS, Banno F, Kashian DR (2012) Invading the invaders: reproductive and other mechanisms mediating the displacement of zebra mussels by quagga mussels. Invertebr Reprod Dev 56:21-32. https://doi.org/10.1080/ 07924259.2011.588015

Ricciardi A, Whoriskey FG, Rasmussen JB (1996) Impact of the (Dreissena) invasion on native unionid bivalves in the upper St. Lawrence River. Can J Fish Aquat Sci 53(6):1434-1444. https://doi.org/10.1139/f96-068

Ricciardi A, Whoriskey FG (2004) Exotic species replacement: shifting dominance of dreissenid mussels in the Soulanges Canal, upper St. Lawrence River, Canada. J North Am Benthol Soc 23(3):507-514. https://doi.org/10.1899/08873593(2004)023\%3c0507:ESRSDO\%3e2.0.CO;2

Rijkswaterstaat (2020) Water logger data. https://waterinfo.rws. nl/\#!/nav/index/. Accessed 2 April 2020

Schonenberg DB, Gittenberger A (2008) The invasive quagga mussel Dreissena rostriformis bugensis (Andrusov, 1879)(Bivalvia: Dreissenidae) in the Dutch Haringvliet, an enclosed freshwater Rhine-Meuse estuary, the westernmost record for Europe. Basteria 72:345-352

Sousa R, Pilotto F, Aldridge DC (2011) Fouling of European freshwater bivalves (Unionidae) by the invasive zebra mussel (Dreissena polymorpha). Freshw Biol
56(5):867-876. https://doi.org/10.1111/j.1365-2427.2010. 02532

Stoeckmann A (2003) Physiological energetics of Lake Erie dreissenid mussels: a basis for the displacement of Dreissena polymorpha by Dreissena bugensis. Can J Fish Aquat Sci 60:126-134. https://doi.org/10.1139/f03-005

Therriault TW, Orlova MI, Docker MF, MacIsaac HJ, Heath DD (2005) Invasion genetics of a freshwater mussel (Dreissena rostriformis bugensis) in eastern Europe: high gene flow and multiple introductions. Heredity 95(1):16-23. https:// doi.org/10.1038/sj.hdy.6800691

Van der Velde G, Rajagopal S, Bij de Vaate A (eds) (2010) The zebra mussel in Europe. Backhuys Publishers, Leiden and Margraf, Weikersheim, p 490

Wesselingh FP, Neubauer TA, Anistratenko VV, Vinarski MV, Yanina T, Ter Poorten JJ, Kijashko P, Albrecht C, Anistratenko OY, D’Hont A, Frolov P, Gándara AM, Gittenberger A, Gogaladze A, Karpinsky M, Lattuada M, Popa L, Sands AF, Van de Velde S, Vandendorpe J, Wilke T (2019) Mollusc species from the Pontocaspian region-an expert opinion list. ZooKeys 827:31-124. https://doi.org/10. 3897/zookeys.827.31365

Zhulidov AV, Pavlov DF, Nalepa TF, Scherbina GH, Zhulidov DA, Gurtovaya TY (2004) Relative distributions of Dreissena bugensis and Dreissena polymorpha in the lower Don River system. Russia Int Rev Hydrobiol 89(3):326-333. https://doi.org/10.1002/iroh.200310727

Publisher's Note Springer Nature remains neutral with regard to jurisdictional claims in published maps and institutional affiliations. 